\title{
Gelişmekte Olan Piyasa Endeksleri Arasında Volatilite Yayılım Etkisinin Analizi
}

\author{
Mehmet Fatih BAYRAMOĞLU* \\ Tezcan ABASIZ**
}

\section{ÖZET}

Bu çalışmada, gelişmekte olan piyasaların borsa endeksleri arasındaki etkileşim, VAR- EGARCH yöntemiyle analiz edilmiştir. 12.03.2013-30.12.2016 dönemini kapsayan çalışmada Morgan Stanly Capital International (MSCI) endeksleri kullanılmış olup, bu endeksler; Brezilya, Meksika, Rusya, Türkiye borsa endeksleri ve Gelişmekte Olan Piyasa Endeksidir. Çallşmada, belirtilen endeks getirileri arasındaki volatilite yayılımı ve varyans değişimi incelenmiştir. Ekonometrik analiz sonuçlarına göre i) AR parametre değerleri piyasalarda yaşanan şokların ardından borsaların getiri hacimlerinde kalıcı sapmaların ortaya çıktığını göstermektedir. ii) piyasalardaki değişimin açıklanmasında kullanılan determinasyon katsayılarının oldukça düşük düzeylerde tahmin edilmesi, piyasaların tümünün zayıf formda etkin olduklarına işaret etmektedir. iii) şokların volatilite üzerindeki asimetrik etkisini ifade eden kaldıraç etkisi; Meksika ve Rusya piyasaları için oldukça yüksek elde edilmiş -negatif şokların pozitif şoklara göre volatiliteyi sırasıyla 5.71 ve $5.01 \mathrm{kez}$ arttırdı̆̆l-ve piyasalar arasında volatilite yayılım mekanizmasının asimetrik olduğu ortaya çıkmıştır. (iv) Brezilya ve Türkiye için piyasalar arası volatilite yayılma etkisi simetrik ancak anlamsız olarak elde edilmiş ve (v) Gelişmekte Olan Piyasa Endeksi öncül endeks olarak belirlenmiştir.

Anahtar Kelimeler: Volatilite Yayılım Etkisi, VAR-EGARCH, Gelişen Piyasa Endeksleri, Şoklara Verilen Tepkime Hızı, Piyasa Etkinliği.

JEL Sinıflandırması: F30, G15, C13, G14.

\section{The Analysis of Volatility Spillover Effect between Emerging Market Indices}

\section{ABSTRACT}

In this study, the interaction between stock market indices of emerging markets was analyzed by VAR-EGARCH method. The volatility spillover and variance change were examined between Morgan Stanley Capital International (MSCI) Indices which are Brazil, Mexico, Russia, Turkey, and Emerging Market Indices, in the period from 3/12/2013 to 12/30/2016. The results of the econometric analysis: $i$ ) $A R$ parameter values show that permanent deviations in the return of the stock indices following the shocks experienced in the markets, ii) estimating very low levels of the coefficient of determination to explain the change in the markets suggests that all of the markets are in the weak-form efficiency, iii) the leverage effect, represents the asymmetric effect of shocks on volatility has been found to be fairly high for Mexican and Russian markets- negative shocks increased volatility by 5.71 and 5.01 times to positive shocks, and the asymmetric volatility spillover mechanism has found, iv) in Brazil and Turkey, the volatility spillover effect between the markets was obtained symmetrically but insignificant, and v) MSCI EM Index was determined as the lead index.

Keywords: Volatility Spillover, VAR-EGARCH, Emerging Market Indices, Speed of Adjustment, Market Efficiency.

Jel Classification: F30, G15, C13, G14.

\footnotetext{
*Yrd. Doç. Dr. Mehmet Fatih Bayramoğlu, Bülent Ecevit Üniversitesi, İktisadi ve İdari Bilimler Fakültesi, fatih.bayramoglu@beun.edu.tr.

** * Yrd. Doç. Dr. Tezcan Abasız, Bülent Ecevit Üniversitesi, İktisadi ve İdari Bilimler Fakültesi, tezcan_abasiz@hotmail.com.
} 


\section{GİRIŞ}

Küreselleşmenin dünya coğrafyasında giderek yaygınlaşmasıyla birlikte, ülkelerin ekonomileri birbirine bağımlı hale gelmiştir. Ancak küreselleşme derecesi açısından ülkelerin birbirlerine göre nispeten farklı olmaları, ülkelerin finansal piyasalarında farklı etkilere neden olabilmektedir (Aityan vd., 2010:590). Son otuz yılda, finansal piyasaların birbirlerine olan bağımlılıkları artış göstermiştir. Hem gelişmiş hem de gelişmekte olan ülkelerde görülen bu eğilim, sermaye hareketlerinin tedricen liberalleştirilmesine, finansal piyasaların serbestleştirilmesine ve yeni teknolojilerin ortaya çıkmasına neden olmuştur (Slimane vd., 2014:3).

Uluslararası finansal piyasaların entegrasyonu yatırımcıları; yeni yatırım firsatları sunma, portföylerini uluslararası ölçekte çeşitlendirme, hendging olanakları ile risk paylaşımında bulunma ve yatırım planları için yeni fon olanakları sunması gibi birçok açıdan desteklemesi bakımından önemlidir (Gamba-Santamaria vd., 2017:2). Ayrıca piyasalar arası etkileşim, bu piyasaların etkinliğinin artmasını sağlayıcı etkilere de sahiptir (Koutmos, 1996:975). Ancak finansal entegrasyonun sağlamış olduğu bu desteklerin, yatırımcılar için bir bedeli olmaktadır. Finansal piyasaların entegre olduğu bir dünyada, ulusal politikaların etkileri sınır ötesine yayılabilmektedir. Özellikle son yıllarda ulusal ölçekte başlayan finansal krizlerin, göstermiş oldukları yayılım etkisiyle birlikte küresel boyutlara ulaştkları görülmüştür. Bu krizlerin en dikkat çekici özelliklerinden birisi, volatilitedeki yayılım etkilerinin ortaya çıkması olmuştur. Dolayısıyla piyasaların birbirlerine olan bă̆ımlılı̆̆ volatilitenin diğer bir piyasayı pozitif ya da negatif olarak etkilemesi sonucunu doğurmuştur (Finta vd., 2017:146; Gamba-Santamaria vd., 2017:2). Dolayısıyla finansal piyasalarındaki volatilite davranışlarını ve kaynaklarını anlamlandırmak, yurtiçi finansal varlıkları fiyatlandırma, küresel riskten korunma stratejilerini uygulama ve varlık dağıtım kararlarını verme süreçlerinde büyük önem taşımaktadır (Ng, 2000:207).

$\mathrm{Bu}$ çalışmada, gelişmekte olan ülkelere ait borsa endeks getirileri arasındaki volatilite yayılımı ve varyanstaki değişim dikkate alınarak piyasaların şoklara verdiği tepkime hızları karşılaştırılmıştır. Çalışmada, Morgan Stanley Capital International (MSCI) veri tabanından elde edilen dört gelişmekte olan ülkenin borsa endeksi ile bir genel endeks kullanılmıştır. Ülke endeksleri MSCI Brezilya, MSCI Meksika, MSCI Rusya ve MSCI Türkiye borsa endeksidir. Genel endeks ise MSCI Gelişmekte Olan Piyasalar Endeksi (MSCI EM Index)'dir. Negatif ve pozitif getirilere göre şokların uyum hızının dikkate alınmasıyla, literatürdeki diğer çalışmalardan farklılaşan bu çalışmada, günlük frekanstaki veri setleri 12.02.2013-30.12.2016 dönemini kapsamaktadır. Çalışma, hem piyasalar arasındaki etkileşimi dikkate alması hem de piyasaları yönlendirme potansiyeline sahip borsaların karşıllıklı etkileşimi sonucu ortaya çıkan öncül ve ardıl (lead-lag) ilişkileri VAR-EGARCH ile modellemeyebilmesi anlamında iki yönlüdür. 
Literatürdeki birçok çalışma, volatilite yayılımının dinamik yönünü dikkate almaktadır. Ancak, toplam volatilite yayılımının etkilerini açıklayabilmek için hem dinamik ve hem eşanlı etkilerin dikkate alınması gerekmektedir. Dinamik etkiler, zamanla ortaya çıkan yayılımları ifade ederken, eşanlı etkiler ise aynı anda ortaya çıkan etkilerdir (Finta vd., 2017:146). Birçok piyasada, işlem saatlerinin örtüşmesi nedeniyle, eşanlı yayılımların yakalanması önem taşımaktadır. Bu nedenle çalışmada hem dinamik hem de eşanlı etkileri dikkate alan VAR-EGARCH modeli, piyasaların karşılıklı etkileşimi ve piyasalar arasında öncül - ardıl ilişkilerin belirlenebilmesi amacıyla tercih edilmiştir.

Literatürde piyasalar arası ilişkileri ortaya koyan VAR-EGARCH modellerinin kullanıldığı teorik makaleler ve bu modellerin çeşitli piyasalara uygulanmasını içeren ampirik çalışmalar bulunmaktadır. Ancak bu çalışmada, piyasalar arasındaki volatilite yayılımı ve varyans değişimlerinin dikkate alınması nedeniyle literatürde genellikle VAR ve MGARCH modellerinin eşanlı olarak kullanıldığı çalışmalara daha çok yer verilmiştir. Bu çalışmalardan başlıcaları aşağıdaki gibidir.

Li ve Giles (2015), ABD, Japonya ve gelişmekte olan altı Asya ülkesine ait getiriler arasında volatilite yayılımını asimetrik bir formda dikkate almış olup, ABD ve Japonya piyasalarından Asya ülke borsalarına doğru istatistiksel olarak anlamlı dolaylı bir etkileşimin varlığına ulaşmışlardır. Ayrıca çalışmada ulaşılan diğer bir bulgu; piyasaların entegrasyonu sonucu, Asya krizi döneminde ABD ve Asya ülke piyasalarında iki yönlü ve güçlü volatilite yayılımı etkisinin varlığıdır. Benzer biçimde diğer bir çalışma Peng vd. (2017) tarafından yapılmış olup Japon borsasının Tayvan borsası getirileri üzerinde etkili olduğu sonucuna ulaşmıştır.

Beirne vd. (2010) çalışmalarında 41 ülke için haftalık getiri frekansında veri setlerini VAR-EGARCH(1,1) yöntemi ile tahmin ederek piyasalar arasındaki karşılıklı bağımlılı̆̆ yayılma etkisinin genel olarak gelişmiş ülke piyasalarından gelişmekte olan ve yerel piyasalara doğru olduğu, ayrıca piyasa getirilerinin risk veya volatilitedeki değişimden kaynaklandığı ifade edilmiştir. Benzer biçimdeki çalışmalara örnek olarak; Booth vd. (1997), Koutmos ve Booth (1995), Ng (2000), Baur ve Jung (2006), Savva (2009) çalışmaları gösterilebilir.

Rao (2008), çalışmasında VAR-MGARCH yöntemi kullanarak gelişmekte olan ülke piyasalarında oynaklığın yatırım kararında etkin bir faktör olduğunu, yatırımcıların portföy çeşitlendirmesine giderek riski minimize etmeye çalıştıklarını ifade etmiştir.

In vd. (2001) için çalışmasında Hong Kong, Güney Kore ve Tayland borsaları volatilite yayılımı ve piyasa entegrasyonu için VAR-MGARCH-BEKK yöntemini kullanarak ilgili piyasalarda, yatırımcının öncül piyasadaki finansal gelişmeleri takip ettiği ve bu anlamda öncül piyasalardaki haber etkisinin diğer piyasalardaki getirinin belirlenmesinde etkin bir faktör olduğu sonucuna ulaşmıştır. 
Khan vd. (2016), çalışmalarında sektörel ve genel düzeyde Pakistan borsası için volatilite şoklarının oldukça yüksek ve süreklilik özelliği taşıdığını ifade etmekle birlikte, sektörel düzeyde farklı derecede etkiler oluşturarak risk ve getiri arasında takasa neden olduğunu ifade etmektedir. Ayrıca şokların en uzun kaldığı sektörler olarak sırasıyla; ilaç sanayi şirketleri, metal sanayi şirketleri ve sigorta şirketleri tespit edilmiştir.

Bekiros (2014) küreselleşme birlikte borç krizlerinin ve finansal krizlerin piyasalar arasındaki yayılımını konu edindikleri çalışmasında BRICS ülkelerine ait piyasa getirilerinde volatilite yayılımı için bahsedilen krizlerin etkili olduğu sonucuna ulaşmışlardır.

Bahsedilen literatürdeki çalışmalar genel olarak değerlendirildiğinde; bulgular, piyasalar arasındaki küreselleşme derecesine bağlı olarak piyasaların karşı1lıklı etkileşimlerinin artış gösterdiği ve bu etkileşimin tek yönlü veya karşllıklı olarak ortaya çıkabileceği yönündedir. Ayrıca, volatilite yayılımının öncül piyasadaki şoklara bağlı olarak diğer piyasaların getiri volatilitesi üzerinde belirleyici bir faktör olduğu ifade edilmektedir.

$\mathrm{Bu}$ çalışmada, gelişmekte olan ülkelere ait borsa endeks getirileri arasındaki volatilite yayılımı ve varyanstaki değişim dikkate alınarak piyasaların şoklara verdiği tepkime hızları VAR-EGARCH modeli ile Brezilya, Meksika, Rusya, Türkiye borsaları için ve MSCI EM Index için test edilmiştir. Çalışmanın izleyen bölümlerinde öncelikle ekonometrik model tanıtılmış, ardından tahmin sonuçları yorumlanmış ve sonuç bölümüne yer verilmiştir.

\section{EKONOMETRIKK MODEL}

Borsa getirileri arasında varyans değişimi ve şokların pozitif-negatif şoklara göre uyum hızlarının test edilmesinde VAR-EGARCH modellerinin bahsedilen ilişkileri dikkate alması, çalışmada bu modelin tercih edilmesine neden olmuştur. Ayrıca ilgili piyasalarda ortaya çıkan şokların büyüklüğünün getiri üzerindeki etkisi ve varyanstaki kırılmanın tarihlenmesi amacıyla otoregresif modeller kullanılmışır.

Varyanstaki kırılmanın dikkate alınarak şokların kalıcılık ya da geçicilik özelliklerinin dikkate alındığı doğrusal bir modelde, varyanstaki kırılmanın modellenebilmesi için 1 nolu eşitlik kullanılabilir.

$$
y_{n i}=x^{\prime} \beta_{n i}+e_{n i}, \quad i=1,2, \ldots, n
$$

1 nolu eşitliğe ait varyans $\sigma^{2}=E\left(e_{n i}^{2}\right)$ şeklinde ifade edilirse yapısal bir değişimin olması durumunda $\beta_{n i}$ parametresinin $x_{n i}$ dağılımına bağlı olarak değişip değişmeyeceğinin test edilmesi gerekmektedir (Hansen, 2000:94). Diğer bir ifade ile $\beta_{n i}$ parametresinde yapısal bir değişim olması durumunda zamana göre varyansın sabit 
kalıp kalmadığı kontrol edilmelidir. Eşitlik 2, gözleme bağlı olan değişimleri göstermek üzere aşağıdaki gibi ifade edilebilir.

$$
\beta_{n i}=\left\{\begin{array}{c}
\beta, i<t_{0} \\
\beta+\theta_{n}, i \geq t_{0}
\end{array}\right\}
$$

Burada $t_{0}$ yapısal değişim zamanını $\theta_{n}$ ise yapısal değişim sonrası parametredeki değişim miktarını göstermekte olup $t_{0} \in\left[t_{1}, t_{2}\right]$ elemanlarından oluşmaktadır. Andrews ve Ploberger (1994) SupF, $\operatorname{Exp} F$ ve AveF testleri 1 ve 2 nolu eşitlikteki ön ilgiler kullanılarak şu şekilde hesaplanır.

$$
\begin{aligned}
& \operatorname{SupF}_{n i}=\sup _{t_{1} \leq t_{0} \leq t_{2}}\left(t_{0}\right) \\
& \operatorname{ExpF}_{n i}=\ln \left(\frac{1}{t_{2}-t_{1}+1} \sum_{i=t_{1}}^{t_{2}} \exp \left(\frac{1}{2} F_{n}\left(t_{0}\right)\right)\right) \\
& \operatorname{AveF}_{n i}=\frac{1}{t_{2}-t_{1}+1} \sum_{i=t_{1}}^{t_{2}} F_{n}\left(t_{0}\right)
\end{aligned}
$$

1 nolu denklemden elde edilen hatalara ait varyansın $\hat{\sigma}^{2}=(n-m)^{-1} \sum_{i=1}^{n} \hat{e}_{i}^{2}$ olduğu ve $m$ 'in $x_{n i}$ 'ye ait vektör sayısını göstermek üzere Eşitlik 1'in yeniden düzenlenmesi gerekmektedir.

$$
y_{n i}=x_{n i}^{\prime} \beta_{n i}+x_{n i}^{\prime} \theta_{n} I\left(i \geq t_{0}\right)+e_{n i}, i=1,2, \ldots, n
$$

6 nolu denklemin EKK yöntemi ile tahmin edilmesiyle $\mathrm{F}$ istatistiği aşağıdaki eşitlikte olduğu gibi hesaplanır.

$$
F_{n i}=\frac{(n-m) \hat{\sigma}^{2}-(n-2 m) \hat{\sigma}_{t}^{2}}{\hat{\sigma}_{t}^{2}}
$$

Yukarıdaki eşitlikte elde edilen F istatistiği 3, 4 ve 5 nolu denklemlerde kullanılarak varyanstaki kırılma Hansen (2000) sabit değişkenli boostrap tekniği ile tespit edilebilir. Buradaki kırılma, değişkenin seviyesinde meydana gelen değişimle ilgilidir. McConnel ve Perez-Quiros (2000) bu yöntemi varyanstaki değişime göre şu şekilde uyarlamıştır. 1 nolu eşitlikteki değişkenin bir AR(1) süreci izlediği varsayılsın.

$$
\Delta y_{t}=\mu+\phi \Delta y_{t-1}+\varepsilon_{t}
$$

7 nolu eşitlikte $\varepsilon_{t}$ 'nin normal dağıldığ varsayımı ile $\sqrt{\frac{\pi}{2}}\left|\hat{\varepsilon}_{t}\right|$ terimi, hata terimine ait standart sapmanın, sapmasız bir tahminci olduğunu ifade etmektedir. 
Dolayısıyla varyanstaki kırılmanın araştırılacağı model basit olarak 8 nolu eşitlikte olduğu gibi yazılabilmektedir.

$$
\sqrt{\frac{\pi}{2}}\left|\hat{\varepsilon}_{t}\right|=\alpha+\mu_{t}
$$

Varyanstaki kırılmanın tahmin edilebilmesi için 7 ve 8 nolu eşitliklerin Genelleştirilmiş Momentler Yöntemi (GMM) altında tahmin edilmesi gerekmektedir. Bunun için öncelikle kırılma dönemini ifade eden yapay değişkenlerin 8 nolu denklem içinde tanımlanması gerekmektedir. Yapay değişkenlerin tanımlandığı bu model 9 nolu denklemde verilmiştir.

$$
\begin{aligned}
& \sqrt{\frac{\pi}{2}}\left|\hat{\varepsilon}_{t}\right|=\alpha_{1} D_{1 t}+\alpha_{2} D_{2 t}+\mu_{t} \\
& D_{1 t}=\left\{\begin{array}{c}
t \leq T \text { ise } 0 \\
t>T \text { ise } 1
\end{array}\right\} \\
& D_{2 t}=\left\{\begin{array}{c}
t \leq T \text { ise } 1 \\
t>T \text { ise } 0
\end{array}\right\}
\end{aligned}
$$

9 nolu denklemlerde yer alan $T, \alpha_{1}$ ve $\alpha_{2}$ parametreleri sırasıyla kırılma dönemi ve kırılma dönemine denk gelen standart sapmaları vermektedir. Boş hipotezin sınanması durumunda $\alpha_{1}, \alpha_{2}$ parametreleri sorun meydana getiren (nuisance-başbelası) parametreler olacağı için Andrews ve Ploberger (1994) çalışmasındaki SupF testlerine başvurulmaktadır. Çalışma, aynı zamanda getirilerin şoklara verdiği tepki hızının negatif ve pozitif getirilere göre ayrıştırılarak 7 nolu eşitliğe ilave varsayım yapılmasını $\varepsilon_{t} \sim N\left(0, \sigma_{t}=d_{0}+d_{1}\right.$ Break $\left._{t}\right)$ gerektirmektedir. Buna göre, varyans değişimine neden olan şokların negatif ve pozitif getiri dönemine etkileşimi kırılmalı olarak test edilebilir.

Ayrıca şokların büyüklüğüne bağlı olarak piyasalar arasında volatilite etkileşimi ve öncül ardıl piyasaların belirlenebilmesi için ARCH-EGARCH yapısı VAR modeli ile uyumlaştırılarak karşılıklı piyasalar arası etkileşim test edilmelidir. Nelson (1991) tarafindan tanıtılan EGARCH yöntemi ile piyasalardaki volatilite iletimi ve yayılma etkisi asimetrik olarak test edilebilir. Ayrıca varyans ve ortalama eşitliklerinden elde edilen inovasyonlar, VAR yöntemi ile sistem haline getirilerek değiş̧kenlerin gecikmeli ve karşılıklı etkileşimleri arasındaki ilişkileri de ayrıca yansıtmaktadır. Geçmiş dönem şokların, cari dönem getiri volatilitesi üzerine asimetrik etkilerinin incelendiği ilk ve öncü çalışmalar Black (1976), Nelson (1991) ve Koutmos (1992) çalışmaları olmakla birlikte metodolojik olarak Koutmos (1996) çalışması bu çalışmada dikkate alınmıştır. Model spesifikasyonu aşağıdaki gibi yazılabilmektedir. 


$$
\begin{aligned}
\text { Getiri }_{i, t} & =\beta_{i, 0}+\sum_{j=1}^{5} \beta_{i, j} \text { Getiri }_{j, t-1}+\varepsilon_{i, t}, i, j=\text { EMindex, Brezilya, Meksika, Rusya, Türkiye. } \\
\sigma_{i, t}^{2} & =\exp \left\{\alpha_{i, 0}+\sum_{j=1}^{5} \alpha_{i, j} f_{j}\left(z_{j, t-1}\right)+\gamma_{i} \operatorname{In}\left(\sigma_{i, t-1}^{2}\right)\right\}, i, j=\text { EMindex, Brezilya, Meksika, Rusya, Türkiye. } \\
f_{j}\left(z_{j, t-1}\right) & =\left(\left|z_{j, t-1}\right|-E\left(\left|z_{j, t-1}\right|\right)+\delta_{j} z_{j, t-1}\right) i, j=\text { EMindex, Brezilya, Meksika, Rusya, Türkiye. } \\
\sigma_{i, j, t} & =\rho_{i, j} \sigma_{i, t} \sigma_{j, t}, i, j=\text { EMindex, Brezilya, Meksika, Rusya, Türkiye. }
\end{aligned}
$$

Getiri eşitliğinde yer alan birinci model spesifikasyonu, analizde yer alan 4 ülkeye ve bir genel endekse ait borsa getirilerinin, her bir piyasa için geçmiş dönem getirileri ile ilişkili olduğunu ifade eden VAR modelidir. Piyasalar arasındaki öncül ve ardıl ilişkiler, ilgili VAR modeli için koşullu ortalama modelinde yer alan $\beta_{i, j}, i \neq j$ katsayıları ile belirlenmektedir. Koşullu ortalama eşitliğinde yer alan ilgili katsayının istatistiksel olarak anlamlı olması, $i$ piyasasının öncül ve $i$ piyasasındaki gelişmelerin $j$ piyasasındaki gelişmelere neden olduğunu ifade edilmektedir. Başka bir ifade ile $j$ piyasasının cari dönem getirisinin, $i$ piyasasındaki beklenen getirinin öngörülmesinde etkin olduğunu ifade etmektedir. Modelde yer alan ikinci eşitlik, her bir piyasasının karşı1ıklı olarak koşullu varyansını göstermekte olup kendi geçmiş döneminin ve diğer piyasaların volatilite etkileşimini göstermektedir. Üçüncü eşitlik ise standardize edilmiş gecikmeli kısmi fonksiyonel biçimi göstermektedir. Eşitlikte $z_{j, t-1}\langle 0$ koşulunda fonksiyon $-1+\delta_{j}$ değerine eşit iken $z_{j, t-1}>0$ durumunda $1+\delta_{j}$ eğim değerine eşit olmaktadır. Dolayısıyla, elde edilen değerlere bağlı olarak standardize edilmiş şokların, her bir piyasa için elde edilen koşullu varyanslarına asimetrik bir etki meydana getireceği ifade edilir. Bahsedilen asimetrik etkinin büyüklüğü $\left(\left|z_{j, t-1}\right|-E\left(\left|z_{j, t-1}\right|\right) \alpha_{i, j}\right.$ için tahmin edilen katsayıların işaret büyüklüğüne göre değişebilmektedir. Eğer $\left.z_{j, t-1}\right\rangle E\left(\left|z_{j, t-1}\right|\right)$ ise $\left.\alpha_{i, j}\right\rangle 0$ olması durumunda $z_{j, t-1}$ 'nin $\sigma_{i, t}^{2}$ üzerindeki etkisi pozitif olacaktır. Benzer şekilde kısmi fonksiyonel biçimde gösterilen $\delta_{j} z_{j, t-1}$ terimi işaret etkisini ölçmektedir. $\delta_{j}\langle 0$ ise $j$ borsasındaki kayıpların ardından yüksek bir volatiletinin oluşacağını, sonrasında ise borsanın toparlanacağını ifade etmektedir. $\mathrm{Bu}$ durum kaldıraç etkisini ortaya koymaktadır. Piyasalar arası volatilite yayılımı, modelde $\alpha_{i, j}, i \neq j$ parametrelerine bağlıdır. Negatif $\delta_{j}$ tahmincisinin, pozitif ve istatistiksel olarak anlamlı bir $\alpha_{i, j}$ tahmincisi ile birlikte değerlendirilmesi durumunda $j$ borsasındaki negatif şokların $i$ borsasının getiri varyansı üzerindeki etkisinin pozitif şoklara göre daha yüksek olduğunu göstermektedir. Dolayısıyla volatilite aktarım mekanizması, piyasalar arasında asimetrik olarak işlemektedir. Dördüncü eşitlik, şokların büyüklüğüne bağlı olarak yayılma etkisi ile oluşan borsa getirilerinin korelasyonlarını göstermektedir. 


\section{UYGULAMA}

\section{1. Çalışmanın Amacı}

$\mathrm{Bu}$ çalışmanın amacı, gelişmekte olan sermaye piyasalarında, gecikmeli ve eşanlı olarak ortaya çıkan volatilite yayılımını analiz etmektir. Çalışmanın giriş bölümünde de belirtildiği üzere; dinamik etkiler, zamanla ortaya çıkan volatilite yayılımlarını ifade ederken, eşanlı etkiler ise aynı anda ortaya çıkan etkilerdir (Finta vd., 2017:146). Dolayısıyla, çalışmada şokların büyüklüğüne bağlı olarak borsa endeks getirileri arasında şokların yayılımı ve uyum hızlarının piyasalar arası karşıllklı etkileşiminin ortaya konulması amaçlanmıştır. Bu amaç doğrultusunda, gelişmekte olan ülkelere ait borsa endeks getirileri arasındaki volatilite yayılımı ve varyanstaki değişim dikkate alınarak piyasaların şoklara verdiği tepkime hızları Brezilya, Meksika, Rusya ve Türkiye'nin içinde bulunduğu dört gelişmekte olan borsa endeksi ve bir genel endeks (MSCI EM Index) için VAR-EGARCH yöntemi ile analiz edilmiştir

\subsection{Veri Seti}

Çalışmada Morgan Stanley Capital International (MSCI) veri tabanından elde edilen dört gelişmekte olan ülke endeksi ile bir genel endeks kullanılmıştır. Ülke endeksleri MSCI Brezilya, MSCI Meksika, MSCI Rusya ve MSCI Türkiye borsa endeksidir. Genel endeks olan MSCI EM Index ise MSCI Gelişmekte Olan Piyasalar Endeksi (MSCI Emerging Market Index)'dir (MSCI, 2017). Çalışmanın bundan sonraki kısmında MSCI EM Index için yalnızca "EM Index" ifadesi kullanılmıştır.

Çalışmada günlük frekanstaki veri setleri 12.02.2013-30.12.2016 dönemini kapsamaktadır. Çalışmada kullanılan borsa endeksleri için getiri değerleri $100 * \ln \left(R_{t} / R_{t-1}\right)$ dönüşümü kullanılarak elde edilmiştir. Grafik 1'de çalışma döneminde ilgili endekslere ait getiriler gösterilmiştir. 
Grafik 1. Çalışma Kapsamına Dahil Edilen MSCI Endeks Getirileri (12.2.13 30.12.16)
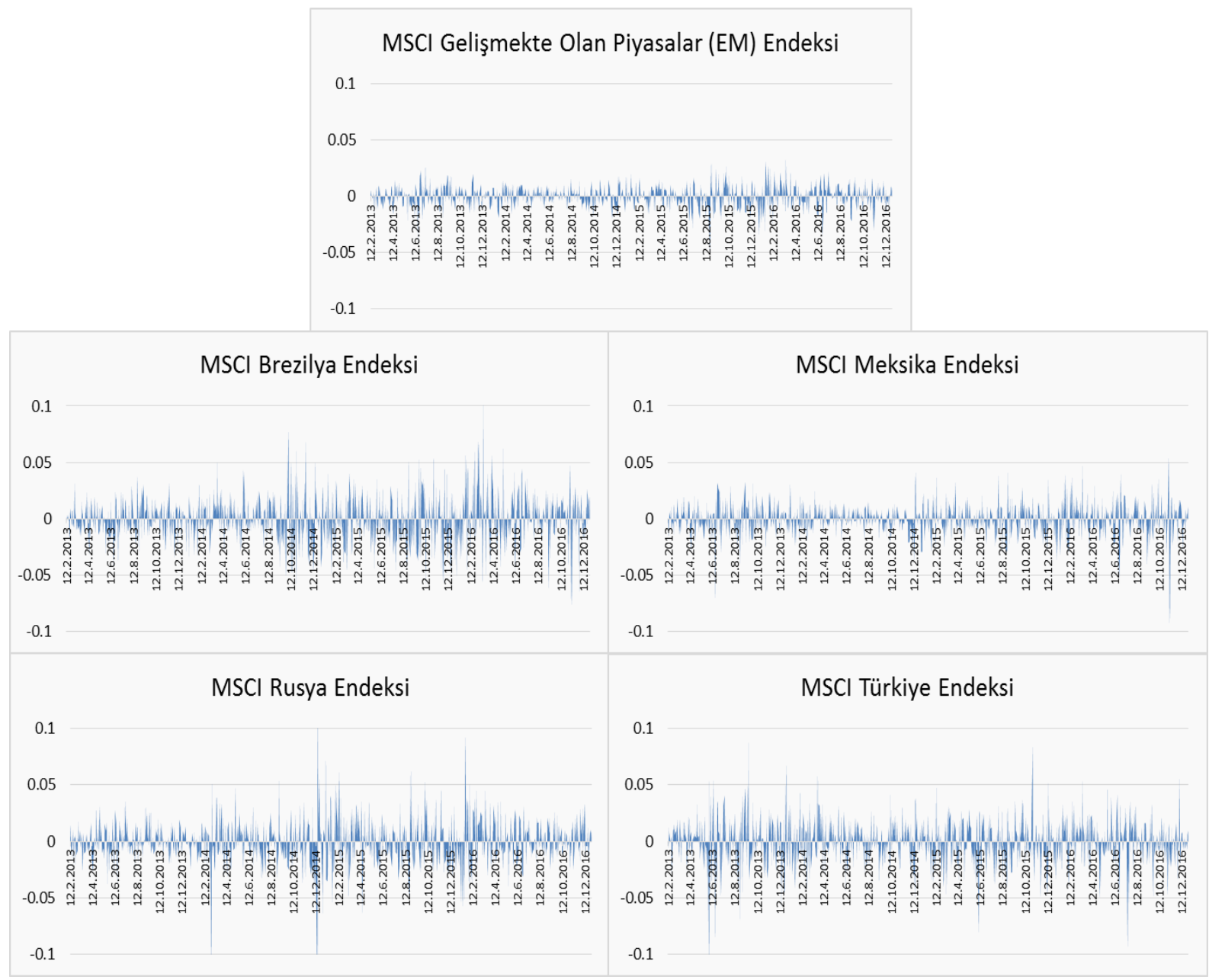

Negatif ve pozitif getirilere göre şokların uyum hızının dikkate alınmasıyla, literatürdeki diğer yöntemlerden farklılaşan bu çalışmada, ekonometrik analizler için WinRATS 9.1 Paket Programı kullanılmıştır. 


\subsection{Tahmin Sonuçlarının Değerlendirilmesi}

Borsa endeks getirilerinin şoklara verdiği tepki hızının otoregresif modeller ile tahmin edildiği sonuçlar Tablo 1'de gösterilmiştir.

Tablo 1: Borsa Endeks Getirileri Arasındaki Etkileşim ve Oynaklıktaki Kırılma

\begin{tabular}{|c|c|c|c|c|c|c|}
\hline & DEĞİŞKENLER & EM INDEX & BREZILYA & MEKSİKA & RUSYA & TÜRKIYE \\
\hline \multirow{9}{*}{ 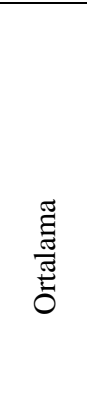 } & $\mathrm{AR}(1)$ & -0.0031 & 0.1508 & -0.0063 & -0.0264 & 0.0131 \\
\hline & P-Değeri & 0.8837 & 0.0059 & 0.8326 & 0.5685 & 0.8167 \\
\hline & Toplam & 0.0004 & 0.0003 & 0.0001 & 0.0003 & 0.0009 \\
\hline & Negatif Getiri (NG) & -0.1506 & -0.3324 & -0.1784 & -0.2793 & -0.4311 \\
\hline & Pozitif Getiri (PG) & 0.1256 & 0.3670 & 0.3419 & 0.3259 & 0.4134 \\
\hline & NG-PG Eşitliği & 0.0001 & 0.0000 & 0.0000 & 0.0001 & 0.0000 \\
\hline & Kırılma Öncesi (KÖ) & -0.0013 & 0.0006 & -0.0002 & 0.0034 & -0.0138 \\
\hline & Kırılma Sonrası (KS) & 0.0031 & -0.0009 & 0.0000 & -0.0008 & 0.0047 \\
\hline & KÖ-KS Eşitliği & 0.4765 & 0.4966 & 0.4991 & 0.4913 & 0.4616 \\
\hline \multirow{7}{*}{ 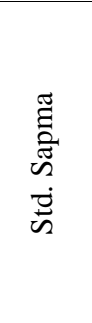 } & Toplam & 1.1444 & 2.7982 & 1.7679 & 2.6513 & 2.7862 \\
\hline & Negatif Getiri (NG) & 1.1039 & 2.8464 & 1.6725 & 2.4699 & 2.6183 \\
\hline & Pozitif Getiri (PG) & 1.1621 & 2.6967 & 1.8913 & 2.8133 & 2.8788 \\
\hline & NG-PG Eşitliği & 0.2530 & 0.2266 & 0.0076 & 0.0034 & 0.0334 \\
\hline & Kırılma Öncesi (KÖ) & 0.9428 & 1.9050 & 1.6121 & 1.5810 & 3.3853 \\
\hline & Kırılma Sonrası (KS) & 1.4029 & 3.2462 & 2.0024 & 2.9329 & 2.4840 \\
\hline & KÖ-KS Eşitliği & 0.0000 & 0.0000 & 0.0000 & 0.0000 & 0.0000 \\
\hline \multicolumn{7}{|c|}{ Oynaklık Kırılma Analizi } \\
\hline & Tarih & 24.6 .2015 & 19.8 .2014 & 17.7 .2015 & 10.2 .2014 & 11.4 .2014 \\
\hline & SupF & 0.0257 & 0.0000 & 0.1706 & 0.0000 & 0.6721 \\
\hline & $\operatorname{Exp} F$ & 0.0086 & 0.0000 & 0.0618 & 0.0000 & 0.4051 \\
\hline & AveF & 0.0121 & 0.0000 & 0.0341 & 0.0000 & 0.3183 \\
\hline \multicolumn{7}{|c|}{ Kırılma Öncesi ve Sonrası Dağılımın Eşitliği: Kolmogorov-Smirnov Testi } \\
\hline & İstatistik Değerler & 0.1238 & 0.1404 & 0.0738 & 0.1199 & 0.0724 \\
\hline & Kritik Değerler & 0.0788 & 0.0788 & 0.0795 & 0.0879 & 0.0838 \\
\hline \multicolumn{7}{|c|}{ Kırılma Öncesi ve Sonrası Kartillerin Eşitliği: Wilconxon Testi } \\
\hline \multirow{4}{*}{ 昜 } & Toplam & -0.7443 & -1.7390 & -1.0561 & -1.4708 & -1.6198 \\
\hline & Kırılma Öncesi (KÖ) & -0.6349 & -1.3006 & -1.0065 & -1.0055 & -1.7822 \\
\hline & Kırılma Sonrası (KS) & -0.9538 & -2.1036 & -1.1699 & -1.5886 & -1.5575 \\
\hline & KÖ-KS Eşitliği & 0.0000 & 0.0000 & 0.0000 & 0.0000 & 0.0000 \\
\hline \multirow{4}{*}{ 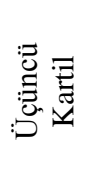 } & Toplam & 0.6504 & 1.7073 & 1.0556 & 1.2984 & 1.6422 \\
\hline & Kırılma Öncesi (KÖ) & 0.5484 & 1.2633 & 0.9146 & 1.0475 & 1.8319 \\
\hline & Kırılma Sonrası (KS) & 0.8443 & 1.9766 & 1.2358 & 1.4647 & 1.5702 \\
\hline & KÖ-KS Eşitliği & 0.1779 & 0.0011 & 0.4447 & 0.2306 & 0.0000 \\
\hline
\end{tabular}

Tablo 1'e göre borsa endeks getirileri için tahmin edilen $A R(1)$ parametre değerleri Türkiye ve Brezilya dışındaki ülke gruplarına ait piyasalarda tamamı negatif işaret büyüklüğüne sahiptir. Yalnız elde edilen tahminciler istatistiksel olarak sıfırdan 
farksız dolayısıyla anlamsızdır. $A R(1)$ parametresinin negatif bir değere sahip olması piyasalarda meydana gelen şokların getiri varyansında oluşan sapmaların kalıcı olmasına ve bu sapmaya neden olan şokun ardından piyasa dengesine döndürecek bir mekanizmanın varlığına işaret eder. İstatistiksel olarak anlamlı $A R$ parametresi Brezilya borsası için geçerli olup öncelikle getiri hacminde meydana gelen sapmaların kalıcı olduğunu ve bu sapmaya neden olan şokun ardından piyasa denge eğilimine döndürecek bir mekanizmanın olmadığına karar verilir. Dolayısıyla piyasalardaki şokun ardından endeks değeri kendi ortalama hızına yakınsayamamakta ve piyasa etkinliği sağlanmamaktadır. Elde edilen sonuçlar, her ne kadar piyasaların etkin olmadığını gösterse de şoklar arasındaki ilişki, getirilerin belirlenmesinde $A R$ parametrelerine göre önemli bir etkiye sahip olduğundan, zayıf veya güçlü formda etkinliğin ortaya çıkabilmesine neden olmaktadır. Bu bulgunun net bir şekilde ortaya konulabilmesi için VAR-EGARCH modelinden elde edilen $R^{2}$ istatistiklerinin yorumlarına ihtiyaç vardır.

Borsa endeks getirileri arasındaki yayılım dikkate alındığında ise ilgili dönem aralığında tüm borsa endeks getirilerinin yatırımcılarına pozitif yönde bir kazanç sağladığı gözlenmektedir. Negatif ve pozitif getirilere göre incelendiğinde en riskli yatırımcı portföyünün sırasıyla Türkiye, Brezilya, Rusya ve Meksika olduğu gözden kaçmamakta ve tarihsel süreçte elde edilen deneyimlerle de bu bulgu büyük ölçüde uyuşmaktadır. İlave olarak riskin yüksek olması elde edilen getirinin de ilgili ülke piyasaları için aynı sıralamada yüksek olduğu da dikkat çekicidir. Pozitif getiri rejiminde ise varyanstaki değişimin Brezilya dışındaki tüm piyasalarda yüksek olduğu gözlenmektedir. Varyanstaki değişimin Brezilya piyasasında negatif getiri rejiminde diğer piyasalara nazaran daha yüksek olması, yatırımcının bu piyasada riski satın alarak daha yüksek getiri elde etmesine neden olmaktadır. Ayrıca bu bulgu istatistiksel olarak da anlamlı bulunmuştur. İlave olarak varyanstaki kırılmanın istatistiksel olarak anlamlı olmadığı tek piyasa Türkiye'dir.

Piyasaları yönlendirme potansiyeline sahip borsaların karşılıklı etkileşimi sonucunda ortaya çıkan öncül ve ardıl (lead-lag) ilişkilerin ortaya konulması amacıyla, VAR-EGARCH yapısı verilen modele ait parametreler, parametre kisitlamasina gidilerek maksimum olabilirlik yöntemi altında tahmin edilmiştir. Elde edilen kısıtlı ve kısıtsız modele ait tahmin değerleri Tablo 2'de toplulaştırılmıştır. 
Tablo 2: Piyasalar Arasındaki Karş1lıklı Etkileșim ve Volatilitenin Yayılım Etkisi

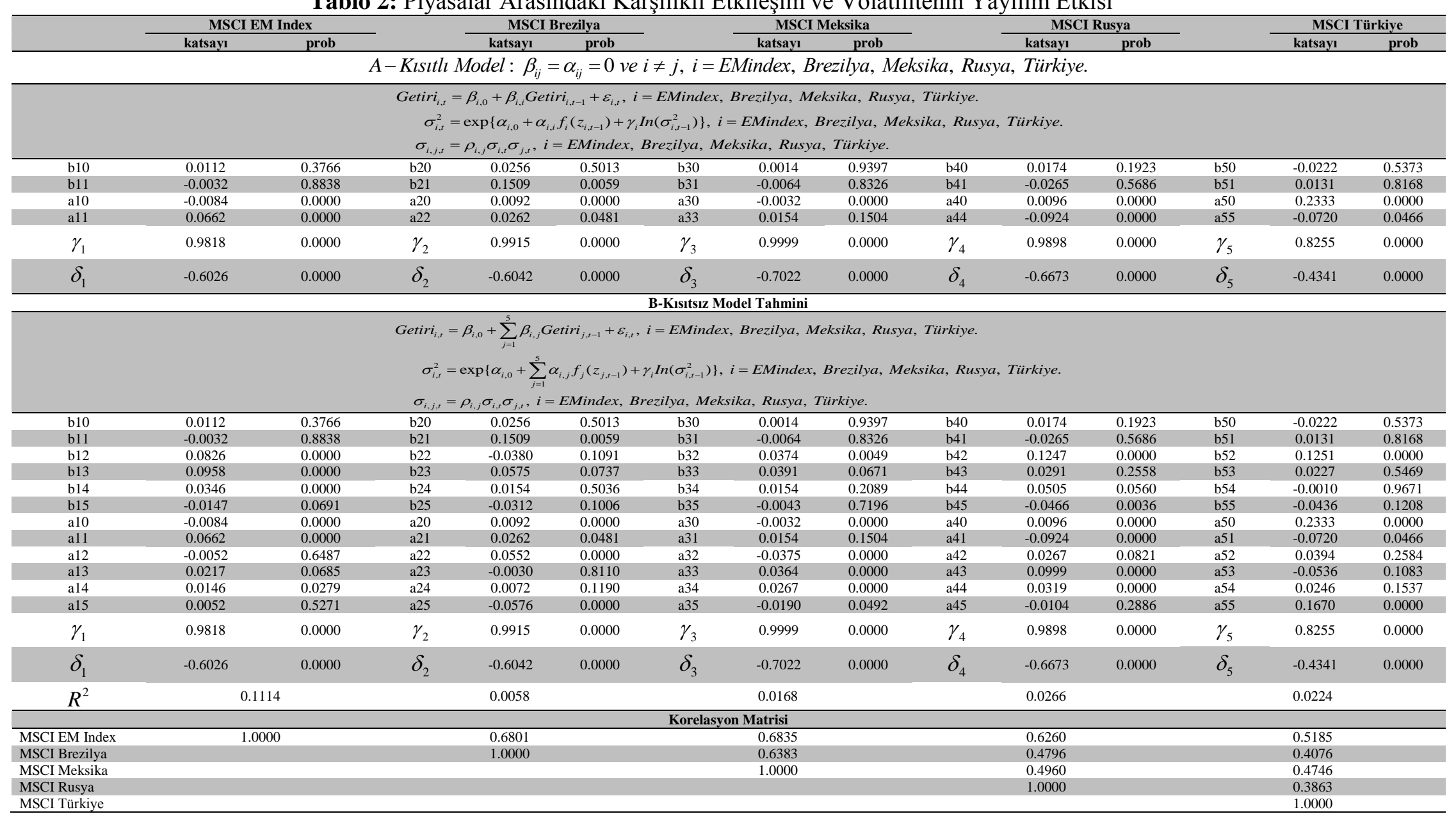


$\beta_{i j}=\alpha_{i, j}=0$ olarak parametrelerin k1sıtlandı̆̆ modelde $A R(1)$ tahmincisi sadece Brezilya borsası için anlamlı gözükmektedir. Bu durum Conrad ve Kaul (1988) çalışmasında ifade edilen zamanla değişen beklenen getiri (time varying expected returns) koşuluna uymaktadır. $\quad \alpha_{i, i}$ parametresine ait tahminci Meksika borsası dışında tüm piyasalarda istatistiksel olarak anlamlı bulunmuştur. Daha açık bir ifadeyle, Meksika borsası dışındaki tüm ülke borsalarında getiri, volatilitedeki değişimden etkilenmektedir. Bu etkilenme daha çok Rusya borsasında gözlenmektedir.

Bununla birlikte GARCH parametresi $\left(\gamma_{i}\right)$ bütün piyasalar için 1'e yakın olup istatistiksel olarak anlamlı bulunmuştur. Getirilerde meydana gelen dalgalanmanın uzun dönemde beklenen getiri üzerindeki değişimi de etkileyeceğini ifade etmektedir. Şokların volatilite üzerindeki asimetrik etkisini ifade eden kaldıraç etkisi; Meksika $(-0.7022)$ ve Rusya (-0.6673) piyasaları için oldukça yüksek olup, negatif şokların pozitif şoklara göre volatiliteyi sırasıyla yaklaşık olarak 5.71 ve 5.01 kez arttırdığ 1 gözlenmektedir. Bu bulgular, Tablo 1'deki sonuçlarla da örtüşmektedir. Şöyle ki; parametrelerin kısıtlanmadığı modele ait tahminlerin gösterildiği tablonun $B$ panelinde $\beta_{i j}, i \neq j$ parametreleri için tahmin edilen değerlerin tümü istatistiksel olarak anlamlı bulunmuş olup analiz grubu ülkelerdeki tüm borsaları etkilediği, bu anlamda EM Index'in öncül piyasa olarak nitelendirilebileceği ortaya konulmaktadır. EM Index'te meydana gelen negatif şokların Meksika ve Rusya borsalarının getiri varyansı üzerindeki etkisi pozitif şoklara göre daha yüksektir. Dolayısıyla EM Index’ten Meksika ve Rusya borsalarına volatilite aktarım mekanizması, piyasalar arasında asimetrik olarak işlemektedir. Brezilya ve Türkiye borsasında ise bu durum simetrik olarak ortaya çıkmakla birlikte istatistiksel olarak anlamsız bulunmuştur.

Ayrıca, öncül olarak EM Index’te gözlenen şokların, volatilite yayılımı yoluyla diğer borsalar üzerinde kalma süresi (volatilite şoklarının kalıcılığı); yarı ömür istatistiklerine *** bağlı olarak en uzun süre Brezilya, Meksika ve Rusya borsaları için sırasıyla ortalama 81, 69 ve 67 gün olarak elde edilmiştir. Türkiye içinse şokların ortalama kalış süresi 4 gün olarak hesaplanmıştır. Bir başka ifadeyle, örneğin; EM Index’ten Brezilya endeksine doğru pozitif veya negatif etki, Brezilya endeksi üzerinde ortalama 81 gün devam etmektedir. Dolayısıyla bu çalışma kapsamına alınan borsalar içerisinde yatırımcısı, pozitif ve negatif şoklara en fazla duyarlı olan yatırımcılar, Brezilya borsasına yatırım yapan yerli ve yabancı yatırımcılardır.

Tablo 1'de elde edilen $A R$ parametre değerleri, endeksin piyasalardaki bir şokun ardından kendi ortalama değerlerine geri dönemediğini ifade etmekle birlikte, şoklar arasındaki ilişkinin varlığı, piyasaların etkin olmadığı görüşünü reddetmektedir. $\mathrm{Bu}$ durum, Tablo 2'de elde edilen $R^{2}$ bulgularına göre; getiri varyanslarındaki değişimin açıklanmasında $R^{2}$ istatistiğinin yetersiz oluşu; bir piyasada endeksin $t+1$ dönemine ait beklenen getirisini, geçmiş dönem getirilerini kullanarak öngörmenin, diğer bir ifadeyle teknik analiz yönteminin

*** Yarı Ömür İstatistiği $=H L=\ln (0.5) / \ln \left(\gamma_{i}\right)$ 
uygulanabilirliğinin, düşük bir ihtimal dahilinde olduğunu ortaya koymaktadır. Dolayısıyla piyasa getirilerinin tahmin edilmesi zorlaşmakta, bu nedenle de ülke borsalarının zayıf formda etkin olduğu ortaya çıkmaktadır.

\section{SONUÇ}

Bilgi ve iletişim teknolojilerinde meydana gelen hızlı gelişmeler, bilginin anında kullanımına bağlı olarak yatırımcıların karar verme süreçlerinde önem arz etmektedir. Piyasaların günümüzde bütünleşmiş olmaları, getiri ve volatilite değişimlerinden tek yönlü veya karşılıklı olarak eşanlı ve/veya dinamik (gecikmeli) etkilenmelerine neden olmaktadır.

$\mathrm{Bu}$ çalışmada dört gelişmekte olan piyasanın (Brezilya, Meksika, Rusya, Türkiye) ve bir genel endeksin (MSCI EM Index) dinamik ve eşanlı olarak ortaya çıkan volatilite yayılımının analizinin amaçlandığı belirtilmişti. Dolayısıyla, çalışmada şokların büyüklüğüne bağlı olarak borsa endeks getirileri arasında şokların yayılımı ve uyum hızlarının piyasalar arası karşılıklı etkileşiminin ortaya konulması da amaçlanmıştı. Çalışmanın amaçları, elde edilen bulgular çerçevesinde değerlendirildiğinde;

(i) Dinamik (Gecikmeli) ilişkiler açısından; EM Index, tüm piyasaları gecikmeli olarak etkilemesi bakımından öncül piyasadır. EM Index'i ise bu piyasalardan sadece Brezilya etkilemektedir. $\mathrm{Bu}$ nedenle EM Index ve Brezilya arasında karşılıklı, EM Index ile diğer piyasalar arasında ise tek yönlü ilişki söz konusudur. Diğer tüm piyasalar ise ardıl piyasalar olarak değerlendirilmektedir. Dolayısıyla, ardıl piyasalarda işlem yapan yatırımcıların, gelişmekte olan tüm piyasaların bileşkesi konumundaki EM Index'i dikkate alarak yatırımlarını yönlendirebilmesi söz konusudur. Ardıl piyasalarda durum; "Brezilya, Meksika ve Türkiye'yi"; "Meksika, Brezilya'y1"; "Rusya, Brezilya ve Türkiye'yi"; "Türkiye ise Brezilya'yı" etkilemektedir. Dolayısıyla, "Brezilya ve Meksika" ile "Brezilya ve Türkiye" birbirlerini karş1lıklı ve gecikmeli olarak etkilemektedir. Diğer piyasalarda ise belirtilen tek yönlü ilişkiler söz konusudur.

(ii) Eşanlı ilişkiler açısından; Öncül piyasa olan EM Index, Meksika ve Rusya'yı etkilemektedir. EM Index ise Brezilya, Rusya ve Türkiye'den eşanlı olarak etkilenmektedir. Dolayısıyla EM Index ile Rusya arasında eşanlı ve karşılıklı etki bulunurken, diğer piyasalarda ise eşanlı ve tek yönlü ilişki söz konusudur. Ardıl piyasalarda durum; "Brezilya, Türkiye'yi”; "Meksika, Brezilya, Rusya ve Türkiye'yi”; "Rusya, Brezilya ve Meksika'yı"; "Türkiye ise Meksika'yı" etkilemektedir. Dolayısıyla, "Meksika ile Türkiye"; "Rusya ile Türkiye"; "Meksika ile Rusya" arasında eşanlı ve karşılıklı bir ilişki söz konusudur. Ardıl piyasalar arasında belirtilen diğer eşanlı ilişkiler ise tek yönlüdür.

(iii) Borsaların şoklara verdiği tepkinin uyum hızları açısından; şokların en çok etkilediği ülkelerin sırasıyla; Türkiye, Brezilya, Rusya ve Meksika olduğu gözlenmektedir. Dolayısıyla, bu ülkelerde şoklara verilen tepki hızının yüksek olması, elde edilen pozitif veya negatif getirinin de yüksek olmasına neden olmaktadır. Dolayısıyla, şokların uyum hızına 
bağlı olarak negatif ve pozitif getirinin de yüksek olduğu bulgusu, Khan vd. (2016) çalışması ile desteklenmektedir.

(iv) Pozitif veya negatif volatilite şoklarının kalıcılı̆̆ı açısından; yarı ömür istatistiklerine göre en uzun süre Brezilya, Meksika ve Rusya borsaları için sırasıyla ortalama 81, 69 ve 67 gün olarak elde edilmiştir. Türkiye içinse şokların ortalama kalış süresi 4 gün olarak hesaplanmıştır.

(v) Piyasaların etkinliği açısından; getiri varyansındaki değişimin açıklanmasında kullanılan $R^{2}$ bulgularına göre; çalışma kapsamına alınan tüm piyasalar, analiz dönemi için zayıf formda etkin piyasa görünümüne sahiptir. Çalışmanın bu bulguları Koutmos (1996) ile örtüşmektedir.

Sonuçlar genel olarak değerlendirildiğinde; EM Index'in öncül piyasa olduğu görülmektedir. EM Index’te meydana gelen negatif şokların, Meksika ve Rusya endekslerinin getiri varyansı üzerindeki etkisi pozitif şoklara göre daha yüksektir. Dolayısıyla, EM Index'ten Meksika ve Rusya borsalarına volatilite aktarım mekanizması, piyasalar arasında asimetrik olarak işlemektedir. Brezilya ve Türkiye borsasında ise bu durum simetrik olarak ortaya çıkmakla birlikte istatistiksel olarak anlamsız bulunmuştur. Negatif şokların etkilerinin, pozitif şokların etkilerinden daha yüksek olduğuna ilişki bulgular, Savva vd. (2009) çalışmalarının bulguları ile benzerlikler göstermektedir. Dolayısıyla yatırımcıların, piyasadaki bilgiyi sistematik bir hata yapmaksızın kullanmaları durumunda, pozitif şoklara nazaran negatif şokların var olduğu piyasalarda ortalamanın üzerinde getiri elde etme olanağı daha fazla olmaktadir.

\section{KAYNAKLAR}

Aityan, S.K. - Ivanov-Schitz, A.K. - Izotov, S.S. (2010), "Time-Shift Asymmetric Correlation Analysis of Global Stock Markets", Journal of International Financial Markets, Institutions and Money, 20(5), pp. 590-605.

Andrews, W.K. - Ploberger, W. (1994), “Optimal Tests when a Nuisance Parameter is Present Only Under the Alternative”, Econometrica, 62(6), pp. 1383-1414.

Baur, D. - Jung, R.C. (2006), "Return and Volatility Linkages between the US and the German Stock Market”, Journal of International Money and Finance, 25(4), pp. 598613.

Beirne, J. - Caporale, G.M. - Schulze-Ghattas, M. - Spagnolo, N. (2010), “Global and Regional Spillovers in Emerging Stock Markets: A Multivariate GARCH-in-Mean Analysis", Emerging Markets Review, 11(3), pp. 250-260.

Bekiros, S.D. (2014), "Contagion, Decoupling and the Spillover Effects of the US Financial Crisis: Evidence from the BRIC Markets", International Review of Financial Analysis, 33, pp. 58-69.

Black, F. (1976), "Studies of Stock Market Volatility Changes", Proceedings of the American Statistical Association, Business and Economics Studies Section, pp. 177-181. 
Booth, G.G. - Martikainen, T. - Tse, Y. (1997), "Price and Volatility Spillovers in Scandinavian Stock Markets", Journal of Banking \& Finance, 21, pp. 811-823.

Conrad, J. - Kaul, G. (1988), “Time Variation in Expected Returns”, Journal of Business, 61, pp. 409-425.

Finta, M.A. - Frijns, B. - Tourani-Rad, A. (2017), "Contemporaneous Spillover Effects between the US and the UK Equity Markets", Financial Review, 52(1), pp. 145-166.

Gamba-Santamaria, S. - Gomez-Gonzalez, J.E. - Hurtado-Guarin, J.L. - Melo-Velandia, L.F. (2017), Volatility Spillovers among Global Stock Markets: Measuring Total and Directional Effects, Banco de la Republica de Colombia, No. 983, Colombia.

Hansen, B. (2000), "Testing for Structural Change in Conditional Moldels", Journal of Econometrics, 97(1), pp. 93-115.

In, F. - Kim, S. - Yoon, J.H. - Viney, C. (2001), "Dynamic Interdependence and Volatility Transmission of Asian Stock Markets: Evidence from the Asian Crisis", International Review of Financial Analysis, 10(1), pp. 87-96.

Khan, F. - Rehman, S.U. - Khan, H. - Xu, T. (2016), "Pricing of Risk and Volatility Dynamics on Emerging Stock Market: Evidence form Both Aggregate and Disagregate Data”, Economic Research, 29(1), pp. 799-815.

Koutmos, G. (1996), "Modeling the Dynamic Interdependence of Major European Stock Markets", Journal of Business Finance \& Accounting, 23(7), pp. 975-988.

Koutmos, G. - Booth, G.G. (1995), “Asymmetric Volatility Transmission in International Stock Markets", Journal of International Money and Finance,14(6), pp. 747-762.

Koutmos, G. (1992), “Asymmetric Volatility and Risk Return Tradeoff in Foreign Stock Markets", Journal of Multinational Financial Management, 2(2), pp. 27-43.

Li, Y. - Giles, D.E. (2015), "Modelling Volatility Spillover Effects between Developed Stock Markets and Asian Emerging Stock Markets", International Journal of Finance \& Economics, 20(2), pp. 155-177.

McConnel, M.M. - Perez-Quiros, G. (2000), "Output Fluctuations in the United States: What Has Changed Since the Early 1980's?”, The American Economic Review, 90(5), pp. 1464-1476.

MSCI (2017), "End of Day Index Data Search", https://www.msci.com/end-of-day-datasearch, (Erişim Tarihi: 4.1.2017).

Nelson, D. (1991), “Conditional Heteroskedasticity in Asset Returns: A New Approach”, Econometrica, 59, pp. 347-370.

$\mathrm{Ng}$, A. (2000), "Volatility Spillover Effects from Japan and the US to the Pacific-Basin", Journal of International Money and Finance, 19(2), pp. 207-233. 
Peng, C.L - Chung, C.F. - Tsai, C.C. - Wang C.T. (2017), "Exploring The Returns And Volatility Spillover Effect In Taiwan And Japan Stock Markets" Asian Economic and Financial Review, 7(2), pp. 175-187.

Rao, A. (2008), “Analysis of Volatility Persistence in Middle East Emerging Equity Markets", Studies in Economics and Finance, 25(2), pp. 93-111.

Savva, C.S. - Osborn, D.R. - Gill, L. (2009), "Spillovers and Correlations between US and Major European Stock Markets: the Role of the Euro", Applied Financial Economics, 19(19), pp. 1595-1604.

Slimane, F.B. - Mehanaoui, M. - Kazi, I.A. (2014), "Interdependency and Spillover during the Financial Crisis of 2007 to 2009-Evidence from High Frequency Intraday Data”, Ipag Business School Working Paper Series, No. 126, pp. 1-14. 
